\title{
Identidad de género como concepto cotidiano en la infancia temprana
}

\author{
Gender identity as an everyday concept in early childhood
}

\author{
José Carlos Cervantes Ríos ${ }^{1}$ \\ Silvia Chávez García ${ }^{2}$
}

\begin{abstract}
RESUMEN
Es un reporte de investigación cualitativa, la cual se realizó en Puerto Vallarta, México, entre 2015 y 2017. El objetivo principal fue identificar el origen $\mathrm{y}$ evolución de la identidad de género en niños y niñas en la infancia temprana desde el enfoque Histórico-cultural. Se empleó el método de clasificación con 12 niños y 19 niñas entre tres y cinco años. Se aplicaron cuestionarios a 34 madres para evaluar sus expectativas. Como principales hallazgos, las/os infantes no presentan evidencias de una identidad de género y la escuela inhibe respuestas estereotipadas. Madres y padres promueven estereotipos.
\end{abstract}

Palabras-clave: Identidad de género. Concepto cotidiano. Infancia temprana.

\section{RESUMO}

Trata-se de um relatório de pesquisa qualitativa, realizada em Puerto Vallarta, México, entre 2015 e 2017. O objetivo principal foi identificar a origem e evolução da identidade de gênero em meninos e meninas na primeira infância a partir do enfoque histórico-cultural. $\mathrm{O}$ método de classificação foi utilizado com 12 meninos e

\begin{abstract}
It is a qualitative research report, which was carried out in Puerto Vallarta, Mexico, between 2015 and 2017. The main objective was to identify the origin and evolution of gender identity in boys and girls in early childhood from the Historical-cultural approach. The classification method was used with 12 boys and 19 girls between three and five years old. Questionnaires were applied to 34 mothers to assess their expectations. As main findings, children do not present evidence of a gender identity and school inhibits stereotyped responses while parents promote stereotypes.
\end{abstract}

Keywords: Gender identity. Everyday concept. Early chidhood.

19 meninas entre três e cinco anos. Questionários foram aplicados a 34 mães para avaliar suas expectativas. Como principais achados, as crianças não apresentam evidências de identidade de gênero e a escola inibe respostas estereotipadas enquanto os pais promovem estereótipos.

Palavra-chave: Identidade de gênero. Conceito diário. Primeira infância.

\footnotetext{
1 Universidad de Guadalajara, México. ORCID: https://orcid.org/0000-0002-0222-5524. Email: josephk50@hotmail.com.

${ }^{2}$ Investigadora independiente, México. ORCID: https://orcid.org/0000-0003-2635-1928. E-mail: schavez@aspv.edu.mx.
} 


\section{Introducción}

En otro espacio (CERVANTES; CHÁVEZ, 2017) se plantearon cuestionamientos a las teorías psicológicas que explican el origen de la identidad de género entre los tres y cinco años de edad -Psicoanálisis, Desarrollo Cognitivo, Aprendizaje Social, Teoría del Esquema de Género- y la necesidad de establecer hipótesis de investigación desde el enfoque Histórico-cultural que permitieran generar un esclarecimiento más preciso de este tema.

Este cuestionamiento se basó en las investigaciones de Vygotski (1993; 1995) sobre el desarrollo de conceptos y el hallazgo de que en las edades antes mencionadas estos sólo se encuentran en estado incipiente. La hipótesis de trabajo fue: no existe identidad de género en la infancia temprana porque los conceptos aún no se han desarrollado y por lo tanto, se trataría de una falsa identidad ${ }^{3}$.

Vygotski (1996) señalaba la dificultad de establecer una periodización de la infancia desde el punto de vista psicológico porque los criterios se basaban sólo en las manifestaciones y no en la búsqueda del funcionamiento y significado interno de las/os infantes. Elkonin (2009) planteó necesario estudiar el desarrollo en su complejidad evitando adoptar visiones lineales y simplificadas. En consecuencia, este estudio hizo un acercamiento a la identidad de género desde la lógica del pensamiento infantil y no desde comportamientos tipificados que se pueden confundir con señales de procesos acabados.

La atención está centrada en infantes de tres a cinco años porque es donde se ubica la formación de la identidad de género según otras teorías psicológicas (BEM, 1983; KOHLBERG; SCHAFFER, 2000; LAMAS, 2002; DIO BLEICHMAR, 2003; MISCHEL; HERRANZ; SIERRA, 2005), pero además se incorporaron edades anteriores y posteriores como marco referencial de los cambios.

\footnotetext{
${ }_{3}^{3}$ Se propone como falsa identidad de género porque el pensamiento conceptual no se ha consolidado todavía, algo que se argumentará a lo largo de este texto.
} 
El artículo presenta primero un breve análisis para definir la identidad de género; posteriormente se plantea la relación entre conceptos cotidianos ${ }^{4}$ y género. Luego se describe la metodología tanto de la identidad, como de la influencia de madres y padres en la promoción de estereotipos ${ }^{5}$. Después se presentan los resultados y finalmente algunas conclusiones.

\section{2. ¿Qué es la identidad de género?}

El primero en plantear el término fue Stoller (GARCÍA MINA, 2003), quien distinguió dos momentos de su génesis: 'núcleo de identidad' e 'identidad de género'. El primero es la convicción de asumirse mujer u hombre desde la edad aproximada de tres años y una vez surgida, no cambia. Él sostenía que era sólo el inicio del desarrollo psicosexual infantil y en función de la identificación anatómica, se adoptaban roles y estereotipos sexuales. El núcleo surge antes que el infante conozca la diferencia sexo-genital. A partir de esta base se desarrolla la identidad de género como un complejo proceso psicológico y toma más tiempo, conclusión a la que llegó en sus estudios con personas transgénero.

Rocha (2009) señala que el término significa aspectos tan diversos como orientación sexual, roles de género, sexo anatómico, entre otros. No obstante, autores (MARTÍNE; BONILLA, 1999; SCHAFFER, 2000; GARCÍA-MINA, 2003; INFANTE, 2004; HERRANZ; SIERRA, 2005) coinciden en entenderla como la autopercepción de pertenecer a un género en base a sus características anatómicas y como consecuencia de ello se interiorizan discursos, creencias, expectativas, normas y comportamientos considerados propios para un

\footnotetext{
${ }_{4}^{4}$ Para Vygotski son un tipo de conceptos surgidos de la experiencia concreta; se tratará su importancia más adelante.

${ }^{5}$ Los estereotipos de género son creencias subjetivas que se comparten socialmente; surgen al comparar física y psicológicamente a cada grupo sexual, sin que corresponda a la realidad; sirven para prescribir y juzgar a priori, simplificando el funcionamiento social al dar certezas de identidad, entendimiento y control (HERRANZ; SIERRA, 2005; JAYME; SAU, 2004; BREWER; MACRAE, STANGOR; HEWSTONE 1996).
} 
determinado 'sexo'. Esta entidad psíquica se forma en el plano social sobre las condiciones biológicas.

La identidad de género contiene tres componentes generales: uno biológico, otro psíquico y uno sociocultural. El cuerpo es la base material del reconocimiento de las personas. Repercute en la manera en que se categoriza al recién nacido según sus características anatómicas. A partir de ellas, se forma una representación alimentada por acciones, interacciones y verbalizaciones en determinado contexto. Resulta pertinente la distinción hecha por Infante (2004) de que una cosa es identificar el sexo anatómico y otra asimilar contenidos sociales de lo 'masculino' y 'femenino' en una cultura.

De acuerdo a Diamond, Kessler y McKena (JAYME; SAU, 2004) la identidad de género depende en gran medida de la carga social sobre una niña o un niño para buscar una 'compatibilidad' con lo masculino o femenino. Aunque en la mayoría de los casos coincidan las expectativas sociales entre el cuerpo y los sentimientos de pertenencia, en otros no, como en la diversidad sexual.

La identidad de género depende del nivel de conciencia que tiene de sí misma una persona en relación a su ser sexual sintiéndose libre en las distintas maneras de expresarse individualmente. En esta dirección Infante (2004) afirma que la edad en que la mayoría de las teorías psicológicas ubican el origen de la identidad de género -dos o tres años- es sólo su comienzo.

Por su parte, Egan y Perry (FRANZ, 2009) proponen algunos componentes para entender la complejidad de la identidad de género al conceptualizarla como un constructo multidimensional que incluye: conocimiento de pertenencia a una categoría, sentimiento de compatibilidad, sentimiento de presión por la conformidad y actitudes hacia los grupos.

Esto permite plantear la hipótesis de que este tipo de identidad se forma después de la infancia temprana, porque implica representaciones simbólicas que debe elaborar la persona y para ello es condición un desarrollo psíquico capaz de construir un significado de género, no solo como comportamientos estereotipados, sino como consciencia de lo que es, siente y percibe. 


\section{Conceptos cotidianos y género}

Para ubicar el origen de la identidad de género es necesario comprender cómo funciona el pensamiento. De acuerdo a la Psicología histórico-cultural opera a través conceptos. Un concepto es "el conocimiento de los rasgos y propiedades esenciales de los diferentes objetos o fenómenos de la realidad objetiva, así como los nexos y relaciones entre ellos” (SHARDAKOV, 1987, p. 243). Son reflejos de los objetos y producto de elaboraciones racionales y de sus conexiones como parte de un sistema.

Vygotski (1993) propone dos tipos de conceptos: los científicos, surgidos a partir de la influencia de la enseñanza escolar, conscientes porque son verbalizados, analizados, ordenados y jerarquizados. Tienden a formar un esquema de explicación de la realidad en su conjunto a través de diversas disciplinas científicas, aunque tienen poco referente vivencial. Los cotidianos, son producto de la vida diaria, se forman a través de las experiencias, son aconscientes ${ }^{6}$ porque se asumen, no se analizan. Precisamente los conceptos relacionados con el género son de este tipo, gran parte de ellos relacionados con estereotipos, se normalizan y rara vez se cuestionan.

El género es una categoría que abarca conceptos cotidianos. Estos corren el riesgo de quedarse como propiedades simples, formando parte del sistema de creencias que configuran la identidad. Sin embargo, por sus características también son inestables y ofrecen la posibilidad de elevar su nivel conceptual a través de un proceso de análisis intencionado que si se cuestiona y reflexiona sobre ellos pueden precisarse, variar o incluso desecharse.

En relación al origen ontogenético de los conceptos, Vygotski (1995) planteó que el pensamiento y la palabra son entidades distintas, pero alrededor de los tres años se fusionan para crear un nuevo proceso: el pensamiento verbal. Su unidad básica funcional, los conceptos. El adulto los presenta al/a niño/a de manera

\footnotetext{
6 Vygotski utiliza el término a-consciente para distinguirlo de los conceptos psicoanalíticos inconsciente y subconsciente. Se refiere al manejo no reflexionado del concepto.
} 
acabada, quien usa palabras pero parcialmente entendibles hasta que alcance un pensamiento abstracto en la adolescencia.

Vygotski (1993) encontró que existe un cambio en la manera en que las personas se apropian de los conceptos culturalmente formados e identificó tres etapas generales en el desarrollo de los mismos: a) cúmulos desorganizados; b) complejos; y c) conceptos. A continuación se presenta un esquema de las características de cada una y sus fases.

Cuadro 1. Etapas de la formación de conceptos

\begin{tabular}{|c|c|c|}
\hline Etapas & Características & Fases \\
\hline \multirow{3}{*}{ I. Cúmulos desorganizados } & \multirow{3}{*}{$\begin{array}{l}\text { Agrupaciones difusas, con } \\
\text { criterios variados, funciona } \\
\text { por ensayo-error. }\end{array}$} & 1) Azarosa \\
\hline & & 2) Percepción visual \\
\hline & & 3) Fusión de las anteriores \\
\hline \multirow{5}{*}{ II. Complejos } & \multirow{5}{*}{$\begin{array}{l}\text { Conexiones objetivas, } \\
\text { vinculadas con la realidad } \\
\text { concreta, son inestables y } \\
\text { dependen de la experiencia } \\
\text { inmediata. }\end{array}$} & 1) Asociativo \\
\hline & & 2) En colecciones \\
\hline & & 3) En cadena \\
\hline & & 4) Difuso \\
\hline & & 5) Pseudoconceptos \\
\hline \multirow{3}{*}{ III. Conceptos } & \multirow{3}{*}{$\begin{array}{l}\text { Conexiones en base a la } \\
\text { abstracción de propiedades } \\
\text { esenciales, son estables. }\end{array}$} & 1) Máxima semejanza \\
\hline & & 2) Potenciales \\
\hline & & 3) Genuinos \\
\hline
\end{tabular}

Fuente: Vygotski (1993)

La infancia temprana corresponde a la etapa en complejos, la cual consiste en que las palabras están ligadas con la realidad concreta y son coherentes con relación al mundo adulto. Sin embargo, estas relaciones son inestables ya que dependen de la experiencia inmediata. A diferencia del concepto que presenta una sola conexión estable, el complejo tiene múltiples vínculos.

Vygotski (1993) planteó una periodización general, sin universalismos, debido a los principios epistemológicos de la Psicología Histórico-cultural: el materialismo histórico. "Las diferentes formas evolutivas coexisten, lo mismo que en la corteza terrestre coexisten estratos de todas las épocas geológicas. Esta tesis 
no constituye una excepción, sino más bien la regla del comportamiento en su conjunto." (VYGOTSKI, 1993, p.171).

Esta metáfora explica la ley general que rige el psiquismo humano, dicha afirmación aplica en el desarrollo de los conceptos: "Cuando el niño domina la forma superior de pensamiento -el pensamiento en conceptos-, tampoco se desprende de otras formas más elementales [...] Incluso el adulto [...] está muy lejos de pensar siempre en conceptos. Con frecuencia, su pensamiento se realiza a nivel de complejos" (VYGOTSKI, 1993. p. 171). Con esto se reconoce que el mundo psíquico infantil y adulto no son totalmente diferentes, lo que echa por tierra la posibilidad de discriminación implícita presente en otras teorías psicológicas que toman como punto ‘ideal' de referencia al adulto.

\section{Metodología}

Bajo el supuesto de que para formar una identidad es requisito conceptualizar, ya que permite el desarrollo de cierta conciencia sobre sí misma/o y las/os demás en términos de 'ser niño o niña', el propósito era ubicar el cambio de conceptos cotidianos de género en la infancia temprana.

Para ello era necesario un método que superara la simple solución de tareas sin mediación de la palabra y también evitar la sola verbalización que dejara fuera la lógica del pensamiento (VYGOTSKI, 1993). Estas características las posee el método de clasificación (LURIA, 1995) que consiste en agrupar imágenes y decir las razones al hacerlo.

Se diseñó una adaptación para identificar el componente de género. Todas las imágenes fueron objetos familiares al alcance del conocimiento y experiencia de personas de cualquier edad. Éstas reflejaban intencionalmente estereotipos de género porque pretendía detectar qué tanto influían al hacer las agrupaciones.

Para ello se emplearon 24 fotografías a color de $15 \times 10 \mathrm{~cm}$, que se podían clasificar en seis grupos: a) personas [mujer, hombre, niña y niño]; b) accesorios [diadema rosa, gorra de beisbol azul, labial rojo y rastrillo azul]; c) animales domésticos [gatito negro, gatito gris con moño rosa, galgo inglés negro con 
paliacate rojo al cuello y galgo afgano de pelaje blanco]; d) juguetes [carrito rojo, muñeca vestida de rosa, pelota de colores y balón de futbol]; e) ropa y calzado [vestido rosa, pantalón negro, zapato negro, zapatilla roja]; y f) elementos del reino vegetal [flor, árbol, plátano y manzana].

La hipótesis era que en la primera infancia las agrupaciones obedecerían a una relación de complejos (VYGOTSKI, 1993). Sabiendo que las/os pequeñas/os se rigen por la experiencia concreta, los grupos por género serían aparentes, a causa de la percepción del estereotipo y no de un concepto identidad de género como tal; ya que para ello se necesita de una generalización estable, algo fuera de sus posibilidades.

La muestra relativa a la infancia temprana fueron 29 personas -12 niños y 19 niñas- entre tres y cinco años. Se incluyeron tres menores a tres años porque en la revisión bibliográfica, algunas investigaciones señalaban que desde el primer año niñas/os son capaces de incorporar estereotipos de género en su lenguaje impresivo antes que el expresivo donde se formulan las primeras palabras (SERBIN, et al., 2001; POULIN-DUBOIS, et al, 2002).

Todas/os las/os menores provenían del estrato socioeconómico medio. Las niñas/os de uno a tres años asistían a una guardería subrogada ${ }^{7}$ y las/os de cuatro a seis a escuela pública de nivel preescolar. Se respetó la voluntad de participación de las/os infantes, como lo sugiere el procedimiento ético de investigación en este grupo etario. (DELVAL, 2001).

Aunque el interés era ubicar la aparición de la identidad de género en la infancia temprana, se amplió la muestra a otras edades como seguimiento de su desarrollo. Por eso se incluyeron personas entre seis y 60 años de ambos sexos. En la siguiente tabla se presentan las características sintetizadas de la muestra total.

\footnotetext{
7 Un servicio subrogado en México significa que el gobierno, para cubrir la demanda, paga a una institución particular que ofrezca gratis la atención a los trabajadores.
} 
Cuadro 2. Características generales de la muestra

\begin{tabular}{|c|c|c|c|}
\hline Etapa & Cantidad & Sexo & Rango de edades \\
\hline Bebés & 3 & $\begin{array}{c}2 \text { niñas } \\
1 \text { niño }\end{array}$ & $\begin{array}{c}\text { De un } 1 \text { año } 3 \text { meses a } 2 \\
\text { años, } 8 \text { meses }\end{array}$ \\
\hline $\begin{array}{c}\text { Infancia } \\
\text { temprana }\end{array}$ & 29 & $\begin{array}{c}17 \text { niñas } \\
12 \text { niños }\end{array}$ & De 3 a 5 años \\
\hline Infancia & 14 & $\begin{array}{c}9 \text { niñas } \\
5 \text { niños }\end{array}$ & De 6 a 11 años \\
\hline Adolescentes & 11 & $\begin{array}{c}4 \text { muchachas } \\
7 \text { muchachos }\end{array}$ & Entre 12 y 17 años \\
\hline Adultos & 16 & $\begin{array}{c}8 \text { mujeres } \\
8 \text { hombres }\end{array}$ & Entre 19 y 60 años \\
\hline Total de personas & 73 & $\begin{array}{c}40 \text { sexo femenino } \\
33 \text { sexo masculino }\end{array}$ & Entre 1 y 60 años \\
\hline
\end{tabular}

Fuente: elaboración propia

En relación al procedimiento, se acomodaron las fotografías aleatoriamente de manera que fueran visibles de forma simultánea. A las/os bebés de uno y dos años, se les presentaron las imágenes por pares en relación al género, a la misma distancia para que eligieran una, ya que cuando se desplegaron todas, su atención no lograba centrarse en la tarea. En el caso de niñas/os preescolares de tres y cuatro años, primero se les mostraba una a una para que las reconocieran nombrándolas mientras se acomodaban en la mesa, así se aseguraba que todas las imágenes fueran identificadas, pidiéndoles después que las agruparan bajo la consigna 'poner junto lo que va junto'; generalmente se les introducía al principio preguntando ‘junto con qué iría esto [imagen]'. Con los sujetos de 5 años en adelante sólo se pedía que las agruparan. Todas las pruebas fueron filmadas omitiendo el rostro de las personas.

Esta evaluación se complementó con un cuestionario. Álvarez-Gayou (2003) señala que usualmente este instrumento de investigación es común en el paradigma cuantitativo, pero también es factible emplearse en estudios cualitativos. El nuestro constaba de 51 preguntas abiertas y cerradas que se agruparon en ocho criterios: información general sobre el contexto del/a menor; autoetiquetado por género; juguetes y manera en que los usan; observación de 
actividades cotidianas de madres y padres; ropa y arreglos usados para resaltar o no su condición género; características de su espacio físico inmediato; expectativas que tienen sobre ellas/os; y acceso a la televisión.

El cuestionario se aplicó a 34 madres de 17 de niñas y 17 de niños, con edades entre un año seis meses y cuatro años cinco meses, de estrato económico medio. La intención era conocer la tendencia a la exposición de estereotipos, lo que corresponde a la lógica de los estudios cualitativos (ÁLVAREZ-GAYOU, 2003). A continuación se presentan los resultados obtenidos en las pruebas de clasificación de imágenes por grupos de edades, complementando después con la información de los cuestionarios aplicados a las madres.

\section{Resultados}

\subsection{Identidad de género}

Se comprobó que en la infancia temprana, niñas/os agrupan imágenes en complejos (VYGOTSKI, 1993). La clasificación correspondía a conceptos cotidianos, de modo que las conexiones se hicieron en función de su experiencia personal. También se observa el uso de estereotipos de género en algunos casos.

\section{a) Primera infancia (1 y 2 años)}

La/os bebés de un año no pudieron agrupar imágenes. Su lógica se rige por impresiones visuales sin estabilidad, no consiguen hacer una elección porque ésta depende de condiciones como la proximidad del objeto con su mano o la intensidad del estímulo -color o forma-; su actividad mental es la percepción (Vygotski, 1993) de modo que les fue imposible dar significado a las fotografías y menos asignarles género.

La pequeña de dos años apenas logró finalizar la tarea porque sus periodos de atención eran cortos. El desarrollo de su lenguaje le permitió hacer una selección preferencial que influye en la estructura de la percepción visual-directa, porque los infantes a esta edad ya distinguen la función de cada objeto (Vygotsky,1996); de esto se deduce que las elecciones de ella están relacionadas con los objetos que 
tienen un papel activo en su vida cotidiana. Eligió todas las imágenes 'femeninas' tal vez por la exposición de estereotipos.

\section{b) Infancia temprana (3 a 5 años)}

De 29 niños y niñas de esta edad, excepto un caso, las/os demás no fueron capaces de etiquetar sus agrupaciones, mostrando un pensamiento en complejos; principalmente asociativos, de colección y difusos. Solo una niña de 5 años hizo toda su clasificación por color dando nombre a cada categoría, aunque la identificación del atributo no era estable probando con ello que su conceptualización estaba en transición a los pseudoconceptos.

Las agrupaciones de objetos obedecieron a una relación práctica y afectiva referida a su experiencia concreta, eran recuerdos de vivencias; es así porque en esta edad domina la memoria (Vygotski, 1996). Al preguntarles por qué sus decisiones, las respuestas eran: 'el árbol está en la calle’, ‘yo tengo un perro’ o ‘yo me comí uno de esos [plátano]'.

También agruparon por vínculos de acción entre personas u objetos: 'el papá compra carros', 'con el zapato pateas el balón', 'la manzana crece en el árbol', 'los perros persiguen a los gatos', 'la niña vive con su papá y su mamá'; o bien a la pertenencia de objetos a personas: 'el vestido es de la niña', 'es de la mamá [señalando el labial]' o 'la flor es de mamá'.

Otro rasgo fue la identificación que hacían de sí mismas/os con la imagen de niña/o. Invariablemente llamaban 'mamá' a la mujer y 'papá' al hombre; esta tendencia se mantuvo en infantes de tres años, presentándose rara vez en los de cuatro y cinco, quienes les nombraban hombre/mujer o eventualmente señor/a. Una niña de tres años dice que el niño se parece a Kenneth su hermano, la mujer a su mamá y el hombre a su papá. Una pequeña de 3 1⁄2 años relaciona: ella es la niña, el niño es su primo, el hombre y la mujer son sus padres, su mamá tiene labial y zapatillas, su papá pantalón, zapatos y rastrillo, hay una flor en su casa, etc.

A la edad de 4 años, los infantes comienzan a observar atributos como color o forma, pero no son estables y fácilmente se pierden ante el peso que representa la 
contextualización del objeto ${ }^{8}$. A los 5 años continúan los criterios anteriores, son confusos, pueden relacionar una imagen por la coloración aunque no sea la misma por ejemplo rosa y rojo, negro y azul marino - o fijarse en detalles del entorno de la fotografía. Para ilustrar esto, una niña de 5 años junta los perros 'porque uno es amarillo y otro blanco'. Empareja al hombre y la mujer 'porque tienen blanco' [en el marco de la tarjeta]; un niño de 4 años dice que el balón de futbol y el plátano van juntos 'porque tienen manchas', luego toma el zapato diciendo que es negro pero lo empareja con el hombre 'porque él usa zapatos'.

Aparecen agrupaciones distinguiendo imágenes entre masculino y femenino. Una niña de 3 años dice: 'mi mami usa pinturas' [junta la mujer con el labial], la niña va con su mami, la gatita y la muñeca van con la niña, la diadema también y la pelota, la zapatilla, la flor y el vestido con mi mamá'. Un niño de 3 años dice: 'El balón con el niño porque los niños juegan futbol y las niñas juegan con su gato', la niña y el vestido 'porque se lo pone', agrega la diadema 'porque también se la pone', añade la pelota al grupo del niño porque juega con ella; se le pregunta si las niñas no juegan con pelotas, dice que no.

Aunque esto podría considerarse un agrupamiento por género no lo es porque, primero, el sujeto no ha conceptualizado el término niño/niñahombre/mujer; y segundo, porque obedece a la realidad experimentada como situación cotidiana. Otro ejemplo de esto es un niño de 5 años que pone al hombre y al rastrillo juntos porque '[el hombre] cada vez se raspa la barba', añade el pantalón porque 'él tiene que usar pantalón'; el zapato porque 'también se pone zapatos'; y la gorra porque 'él se quema la cabeza'. Se observa el mandato masculino de usar pantalón, tan común, como ponerse zapatos y gorra para el sol' ${ }^{9}$.

Una niña de 3 años: 'el niño juega con coches' y los junta, luego al ver el labial dice 'esto no va con el papá, va con la mamá'. Otro de 4 años empareja el carrito con el niño 'porque los niños juegan con carritos', se le pregunta si los niños

\footnotetext{
8 La contextualización del objeto se refiere a que, "[...] los signos del contexto son los que estructuran la actividad del sujeto" (Wertsch, 1988, p.116), por ejemplo, en esta etapa los infantes no veían la imagen de una mujer en la tarjeta, veían a una mamá.

9 En Puerto Vallarta la mayor parte del año es soleada y cálido-húmeda, por lo que el uso de gorra con visera es frecuente entre los hombres.
} 
juegan con muñecas y responde un rotundo no; después junta el zapato con el hombre porque 'él usa zapatos' así como el rastrillo; la zapatilla la pone con la mujer porque 'ellas usan esos zapatos'.

Los estereotipos expresados están lejos de ser internalizados como etiquetas simplificadoras y menos aún como medios de discriminación, segregación o jerarquización. Más bien los usan porque es habitual, es una propuesta adulta para interactuar entre las personas.

A medida que estas niñas y niños comienzan a distinguir atributos comunes como color o forma, parecen dejar de lado el estereotipo, aparecen ensayos de agrupaciones distanciadas de la experiencia concreta. Mientras que a los 3 años todos sus grupos relacionan la auto identificación directa, a los 4 hay una combinación con intentos de agrupar por color y a los 5 la proporción es inversa, por lo tanto, se mencionan menos relaciones estereotipadas. No se afirma que los estereotipos de género vayan desapareciendo, una posible explicación es que a medida que avanzan en la escolarización, se favorece su pensamiento categorial desplazándolos a la periferia.

Con todo esto, se confirma que no existe la capacidad de conceptualización en la infancia temprana, por lo que no puede existir una identidad de género; lo que muestran las evidencias son las vivencias que los menores tienen en la interacción con su contexto, donde aparecen rasgos de estereotipos.

\section{c) Infancia (entre 6 y 11 años)}

En esta etapa las clasificaciones de las tarjetas son diferentes. Niños y niñas de estas edades no se limitan a la relación directa con el objeto y aparecen criterios variados. La categorización responde a su comunalidad. Con este término Vygotski (1993) se refiere a la capacidad que tiene el/la menor para percibir los rasgos comunes entre los objetos sin lograr hacer una generalización; por ejemplo, un niño de 6 años forma los siguientes grupos: 'Mujeres' [niña y mujer], 'Frutas' [plátano y manzana], 'Jugar' [carrito, perros, gatos, balón, muñeca y pelota, árbol, niño, flor], 'Zapatos' [zapatilla, zapato, vestido, pantalón, señor, diadema, gorra, labial, rastrillo]; es evidente que se 
distingue un atributo común que reúne los objetos, pero las etiquetas empleadas para nombrar cada grupo indican que no hubo un proceso de abstracción que le permita encontrar el concepto jerárquico superior que sería la categoría. Todos los casos se encontraron en la misma situación.

Con esto se ilustra que niñas/os definen sus categorías sin un concepto, solo responden a una impresión general y funcional (Vygotsky, 1996). Ellas/os definen una fruta como 'lo que comes', zapato 'es algo que te pones en los pies', pelota 'es algo que te sirve para divertirte cuando estás aburrido' o juguetes 'son como una muñeca, un carro y un balón'.

De las/os 13 participantes - cinco niños y ocho niñas- se encontró una tendencia a agrupar y etiquetar con nombres neutrales como: 'juguetes', 'naturaleza', 'balones', 'familia', 'humanos' y 'ropa', siendo el criterio una categoría funcional no estereotipada. Sólo un sujeto nombró a uno de sus grupos como 'mujeres' [mujer y niña], a quienes definió como 'las mujeres compran cosas' y los demás objetos estereotipados femeninos no fueron puestos en el mismo grupo.

En dos casos de nueve años agruparon las imágenes de niño, niña, mujer y hombre bajo el rubro 'personas'; uno definió su categoría como 'humanos' y el otro 'son como mujeres, hombres, etc.'. Por último, la niña de 11 años agrupa bajo la etiqueta 'ropa' el vestido, el pantalón, la diadema, el zapato y la zapatilla; al definir su categoría dice: 'ropa es todo lo de vestir'. Esta forma de organización puede referir a los conceptos potenciales pues está cerca de una generalización.

En este grupo de edad resulta evidente que el papel de la influencia escolar es determinante porque los indicios que aparecían en la etapa anterior, aquí prácticamente desaparecieron y en su lugar emergieron conexiones derivadas de las exigencias académicas para categorizar.

\section{d) Adolescencia (12 a 17 años)}

Para la teoría Histórico-cultural, es durante la adolescencia cuando se alcanzan los conceptos genuinos, pero en el sentido de etapa crítica y madurativa del pensamiento y no de finalización del proceso; "[...] incluso los conceptos utilizados, tanto por el adolescente, como por el adulto, únicamente 
en la esfera de la experiencia cotidiana no suelen superar el nivel de los pseudoconceptos" (VYGOTSKI, 1993, p.171).

Esto explica por qué en la clasificación de conceptos cotidianos vinculados al género aparecieron agrupaciones similares a los complejos. Lo anterior se ilustra en la forma de definir la categoría 'mujer': 'alguien distinto al hombre' [muchacha,12 años]; 'es una señora' [muchacho,12 años]; 'es una persona, una mujer' [muchacha,12 años]; 'es alguien que representa así las cosas para una mujer' [muchacha,12 años]; 'alguien que tiene mucho cariño con las personas, con sus hijos, con sus esposos' [muchacho, 13 años]; 'es algo muy importante en la vida y que representa a la mamá' [muchacho,14 años]. Nociones similares dieron para 'hombre', 'niño' y 'niña'. Como se observa, el concepto cotidiano aparece estereotipado, sin evidencia de haber generalización.

No obstante la similitud entre los complejos en la infancia temprana y adolescencia, guardan características y origen funcional distinto, pues en el infante obedecen a la inmediatez de su experiencia con objetos, cuando en la/el adolescente se deben a la importancia de las reglas sociales en su contexto y la búsqueda de integrarse al mundo adulto.

Esto parece corroborarse porque de los once casos analizados, se encontraron 6 en concordancia con estereotipos, ya fuera en forma total o parcial, solo distinguían el género al vincular a las personas y objetos relacionados con el estereotipo, lo que no hicieron con los animales - aun cuando también tenían señales con estas características - , las frutas y plantas.

En los otros cinco casos, los estereotipos están totalmente ausentes. Una muchacha de 14 años hizo la siguiente clasificación: 'Homo sapiens' [mujer, hombre, niño, niña]; 'felinos' [gatos]; 'canes' [perros]; 'belleza' [rastrillo, vestido, pantalón, zapato, diadema]; y ‘diversión' [pelota, balón, carrito, muñeca]. Ella mezcló conceptos científicos como Homosapiens, felinos y canes, con categorías funcionales propias de los conceptos cotidianos como diversión y belleza.

Otro ejemplo es un muchacho de 16 años, quien formó tres categorías: ‘creados por el hombre’ [rastrillo, diadema, pelota, balón, carrito, labial, vestido]; 'no creados por el hombre' [plátano y manzana] y 'sujetos que tienen vida' [niña, 
niño, mujer, hombre, gatos, perros, árbol, flor]. En este caso, ninguna de las categorías corresponde a la incorporación de estereotipos de género.

Vygotski ilustra el potencial de esta etapa de desarrollo: "El paso al pensamiento en conceptos abre ante el adolescente el mundo de la consciencia social objetiva" (1996, p.64). La escuela cobra relevancia porque el uso de conceptos científicos crea las condiciones para que los conceptos cotidianos de género se liberen de estereotipos al ser sometidos a la generalización, algo que tiene que ser intencionado.

\section{e) Adultez (19 a 60 años)}

La mayoría de las personas adultas hicieron clasificaciones categoriales pudiendo operar con el significado y relaciones de las imágenes sin problema. Esto sin lugar a duda mantuvo los referentes de género en otro plano10, observándose pocos indicios de su influencia. Solo tres de 18 sujetos hicieron agrupaciones con categorías estereotipadas: dos mujeres adultas de 37 y 39 años y un hombre de 42 años. Las dos mujeres agruparon en torno a las imágenes de personas los objetos correspondientes a cada género y edad, los animales y elementos del reino vegetal fueron clasificados aparte. El hombre hizo cuatro grupos alrededor de las personas, incluyó todas las imágenes. Estos agrupamientos corresponden a complejos porque influyeron más los significados personales, que operar con el concepto.

El resto de las agrupaciones se ordenaron por categorías como: mascotas, frutas, juguetes, utensilios, closet, personas o colores. Un joven universitario de 21 años clasifica: 'Con cara, definido como aquello que tiene rasgos faciales, que tiene ojos, nariz, boca, que tiene intención de cara'; y 'Sin cara: lo que no tiene rasgos faciales'. Esto evidencia la capacidad de abstracción de los conceptos, que considera los atributos de los objetos fuera de las conexiones concretas (WERTSCH, 1988) dejando las distinciones de género al margen en tareas como esta.

Lo relevante de estos hallazgos es que cuestionan la instalación definitiva de una identidad de género en la infancia, ya que ningún menor de 11 años mostró

\footnotetext{
${ }_{10} \mathrm{Al}$ final de la prueba se les preguntaba si habían notado la distinción por género en las tarjetas y respondían que sí, pero la mayoría no lo consideró como criterio de clasificación relevante y otros dijeron que no lo notaron.
} 
evidencia de generalizar lo femenino o masculino; podrán tener un uso funcional del concepto hombre/mujer, niño/niña, pero por tratarse de conceptos cotidianos no pueden descontextualizarse y pasar a un nivel de generalización. Si fuera definitivo como asegura la mayoría de la bibliografía sobre género, se hubiesen encontrado clasificaciones en todas estas edades en función de dicha distinción y no fue así. Sólo se observa parcialmente en el grupo de las/os adolescentes y en menor medida en la adultez.

Es pertinente preguntar cómo es que los comportamientos tipificados por género se exhiben desde una edad temprana y las/os bebés parecen distinguir, actuar e identificarse con el sexo que biológicamente les corresponde de acuerdo a varias investigaciones (PUOLIN-DUBOIS, et al., 2002; WALKERANDREWS; RAGLIONI; DÍAZ en HERRANZ; SIERRA, 2005). Un intento de respuesta se encuentra en el acercamiento a las madres de menores a través de cuestionarios, que sin pretender ser un estudio exhaustivo, fue útil como resultado complementario.

\subsection{Influencia adulta en los estereotipos de género}

De acuerdo a Blonski (en VYGOTSKI, 1996) al comenzar la fase de dentición, el/la bebé empieza a comprender el comportamiento de los adultos y establece con ellos una comunicación psicológica elemental. Por consiguiente, éste/a se convierte en su centro de observación y fuente de información sobre la realidad.

\section{a) Autoetiquetado}

Investigaciones señalan que hacia los dos años los/as menores son capaces de distinguirse verbalmente a sí y a las demás personas como niña/o (GOLOMBOK \& FIVUSH en SCHAFFER, 2000). Según refieren las madres consultadas en este estudio, son mamá y papá quienes hacen saber a sus hijas/os que son niñas/os. Refieren expresiones como: 'desde que nacieron', otros 'desde siempre', tan pronto se enteraron qué sexo tenía comenzaron a tratarle en consecuencia verbalmente y a través de ciertas características distinguibles como ropa, colores o juguetes. Antes de que el/la niño/a se identifique con un género, es constantemente informada/o por su 
familia a qué bando pertenece. En el caso de los varones, los genitales son un signo útil, en tanto que para las niñas es la ropa y el largo del cabello.

Un hallazgo es que los niños notan la distinción dicotómica de sexos más pronto que las niñas. Una explicación podría ser que los padres se preocupan más porque el varón afirme lo más pronto su masculinidad y para ello ven necesario se distinga de las mujeres, en especial de las madres, ya que para algunos papás significa un riesgo de 'confusión sexual', una creencia sin fundamento.

\section{b) Juguetes}

Una idea aceptada es que desde un año y medio, las/os bebés eligen juguetes dependiendo de la propia tipificación sexual (Houston en Herranz y Sierra, 2005). Las respuestas del cuestionario confirmaron esta idea. Los varones tienen como favoritos los vehículos, mientras que las niñas prefieren muñecas o muñecos de peluche. Los juguetes no llegan espontáneamente a los hogares, son proporcionados por los adultos teniendo en mente el género del destinatario.

El adulto propicia que se mantenga la correspondencia de género. Son mamás, papás y/o hermanas/os mayores quienes enseñan al/a niño/a cómo usar el juguete en un principio. De acuerdo con Vygotsky (1993), el aprendizaje se da en dos planos: interpsicológico - entre personas - e intrapsicológico internalizado individualmente -.

Cuando se trata de juguetes, la observación e imitación permiten al/a bebé interactuar con él. Las madres de niños refieren que ellos no muestran interés en juguetes contrarios a su género, sucede lo inverso con las niñas. Aparece en las respuestas la preocupación de confundir al/a bebé si no le muestran índices de diferenciación claros, especialmente a los varones, de manera que existe negativa a dejarles usar juguetes 'para niñas'. Schaffer (2000) refiere que a ellos se les enseña a evitar aquello que no es varonil lo antes posible.

Vygotski (1979; 1997) y Elkonin (1980) plantearon que el juego no es una actividad espontánea que niñas/os realicen por simple diversión, sino la preparación que les damos los adultos para cuando ellas/os se conviertan en mujeres y hombres 'adaptados a la sociedad' que demanda un modelo a seguir. 


\section{c) Actividades cotidianas observadas}

En este acercamiento las niñas están expuestas a mayor número y más variedad de actividades cotidianas en comparación con los niños; es posible que tenga relación con un modelaje materno más enfocado en las hijas, intencionado o no. Las/os menores de ambos sexos ven a sus madres limpiando la casa, cocinando, vistiéndose y maquillándose; en tanto que a sus padres los ven vistiéndose, bañándose y afeitándose.

Es claro el rol de género tradicional que exhiben estas parejas, se normaliza que las tareas del hogar correspondan a la madre a pesar de que todas ellas tenían un trabajo fuera de casa. Como señala Fine:

[...] un hecho empírico es que los niños nacen en un medio en que la mujer es la principal responsable de satisfacer las necesidades de los niños y de la familia”. (FINE, 2011, p.254).

\section{d) Apariencia}

Una vez que la percepción del bebé comienza a enfocarse en un solo rasgo y prestar importancia a las diferencias, se da cuenta que una forma de orientarse depende de la apariencia de las personas (VYGOTSKI, 1996). "Las convenciones relativas a la ropa y los accesorios implican que el género es algo sumamente obvio desde el punto visual" (FINE, 2011, p.265), haciendo que esta categoría resalte sobre las demás. La marcada distinción entre ropa femenina y masculina, los colores y figuras que le caracterizan y otros objetos de uso personal, imprimen índices de orientación seguros a los que se recurre. Cuando esos índices no son claros el desconcierto suele incomodar al infante (DAVIES, 1994).

A los varones se les vistió de azul y rojo principalmente, teniendo el pantalón y short como prenda masculina. Por su parte las madres adornan a sus hijas con moños, diademas ${ }^{11}$ y vestidos con predominio del rosa, además de otros colores como blanco, azul y morado, según las respuestas. Otra prescripción cultural para

\footnotetext{
11 En los últimos años se ha puesto de moda poner bandas de encaje, con flores o moños, en la cabeza de las niñas desde el nacimiento.
} 
ellas es la perforación de los lóbulos de las orejas; usar aretes a los días de nacer es una forma segura de informar sobre el sexo de la bebé.

Por otro lado todos los niños usaban el cabello corto, de las niñas sólo tres. Las razones de las madres para esto eran relativas a la comodidad e higiene de sus hijos 12: 'por el calor', 'evitar piojos', 'la limpieza', 'lo complicado de desenredarlo'; y si usaban accesorios en la cabeza eran gorras para cubrirse del sol. En cambio en las niñas lo dejaban crecer por razones de belleza: 'porque me gusta', 'para peinarla', 'se ve bonita' y 'es niña'. El clima parece no afectar a las niñas y la belleza que deriva de una larga cabellera importa más que la incomodidad que representa para un chico. El cabello largo aparece como símbolo de belleza femenina a lo largo de la historia como prescripción social (PERROT, 2009).

\section{e) El espacio físico}

Para el menor, su recámara es un referente de observación y si predominan ciertos colores, decoración u objetos que destacan rasgos diferenciados, podría asociarlos con uno u otro género.

Los resultados del cuestionario evidencian que el color azul es predominante en las recámaras de los niños, en tanto que el rosa es para las niñas; el segundo color que predomina en ambos casos es el blanco, que en términos de género sería neutral. Los dormitorios femeninos son los más decorados, con motivos florales principalmente y animales después. La mayoría de los dormitorios de niños no están decorados o lo están con imágenes de carritos y animales también. Estos espacios son dispuestos por los progenitores y suelen estar visiblemente distinguidos.

\section{f) Descripción de los hijos y expectativas parentales}

La descripción en tres palabras que hicieron las madres sobre sus hijas/os en el cuestionario, aparecen con más frecuencia rasgos relativos a un mayor nivel de actividad para los varones: travieso, inquieto, activo, alegre, deportivo, con energía,

\footnotetext{
12 En Puerto Vallarta hace calor desde junio hasta noviembre, las temperaturas se elevan sobre los 30 grados centígrados y la humedad llega hasta el 90\%, por lo que son comunes los brotes de pediculosis.
} 
curioso, juguetón y peleonero. La cualidad de inteligente fue mencionada en dos tercios de los casos, que junto con carismático, sonriente, platicador, con carácter, creativo, atento y compartido, conforman un conjunto de adjetivos propios de una personalidad extrovertida, pública y segura de sí. Esto corresponde al estereotipo masculino, porque al comparar las descripciones para las niñas emerge su contraparte; adjetivos referidos a la belleza y emocionalidad: bonita, chiquita, linda, hermosa, cariñosa, tierna, amistosa, amorosa, enojona, berrinchuda, alegre, espontánea y llorona. No se debe olvidar que se trata de percepciones de las madres sobre sus hijos/as que, en estos casos, parecen estar tradicionalmente estereotipadas.

\section{g) Acceso a la televisión}

Todos/as los/as hijos e hijas en este estudio ven TV; por lo tanto puede afirmarse que es el medio masivo con el que primero se tiene contacto. A decir de las madres, en promedio las niñas pasan 2.5 hrs diarias frente al televisor en comparación con 1 hora de los niños. Lo que más ven son programas de dibujos animados y películas infantiles, cuya selección es hecha por las mamás principalmente.

Casi todos estos hijos e hijas mostraron preferencia por ciertos personajes con tendencia a coincidir con su género. Esto confirma que los niños son activos e interpretan lo que ven frente al televisor, aunque siempre será con la limitación de los referentes que tengan, de manera que se pueden convertir en modelos alternativos a los estereotipos o en un medio que los confirma.

Este acercamiento confirma que los infantes no son quienes construyen estereotipos basados en sus observaciones, como lo sugieren algunas investigaciones (POULIN-DUBOIS, et al., 2002; SERBIN, et al., 2001; SERBIN; POULIN-DUBOIS; EICHSTEDT, 2002) más bien se trata de una exposición a estos como se comprueba en las respuestas de las madres de este acercamiento.

\section{Conclusiones}

Como se observa en los resultados, nuestra hipótesis de trabajo se comprobó: no se detectan evidencias claras de que las/os niñas y niños 
evaluadas/os en la infancia temprana tengan una identidad de género formada como afirman las otras teorías psicológicas. Lo que muestran es un pensamiento en complejos, por eso son tan variadas sus respuestas porque son conexiones diversas que corresponden a la manera en que significan su realidad, pues como afirma Vygotski (1991), cada vivencia es única.

Por otro lado, se observa la influencia del sistema educativo al momento de resolver la tarea de clasificación desde la edad preescolar. Por ejemplo, el hecho de que niñas/os de esta edad eligieran el color - no necesariamente rosa o azul-, forma o tamaño como primer criterio está en los programas escolarizados. Justo por esto la niña de dos años muestra respuestas estereotipadas, porque está ausente el factor escolar.

Si los conceptos son la manera en que vemos e interpretamos el mundo, el hecho de que la mayoría de estas personas de diversas edades hayan agrupado sin emplear estereotipos de género como primera respuesta, demuestra que la exigencia del sistema educativo diluye/inhibe parcialmente las respuestas estereotipadas.

Con esto no queremos decir que los estereotipos desaparecen, sino que se ocultan en un primer momento, pues siguen siendo parte de la información cultural que recibimos y usamos cotidianamente. Así lo revelaron los resultados del cuestionario aplicado a las madres: los padres son los primeros promotores de estereotipos.

La escuela, como otro factor de socialización, si bien no ha sido capaz de promover de manera sistemática la coeducación ${ }^{13}$ en todos sus niveles, sí ha logrado diluir esa respuesta de manera inmediata. A los adolescentes y jóvenes se les preguntaba al finalizar la prueba de clasificación, si pensaron en hacerlo en base al estereotipo de género, la mayoría afirmó que sí lo notaron pero lo resolvieron de otra forma; solo una minoría de los casos en todas las edades excepto en la adolescencia, que fue casi igual- lo hizo así. ¿Por qué? Porque forma parte del bagaje cultural y cuando enfrentamos un problema empleamos

\footnotetext{
${ }^{13}$ Simón y Cremades (2003) la definen como: "Proceso intencionado de intervención a través del cual se potencia el desarrollo de chicos y chicas, partiendo de la realidad de dos sexos diferentes, hacia el desarrollo personal y una construcción social común y no enfrentada". (p.47)
} 
todos nuestros recursos, en este caso, los que nos proporciona la educación formal. Por lo tanto, se debe reconsiderar su importancia sobre el desarrollo conceptual de género, pues propicia el avance del pensamiento categorial que manifestaron la mayoría de los sujetos escolarizados. Esto posibilita la generalización de conceptos cotidianos, que sería una base cultural para el análisis y el cuestionamiento de los estereotipos de género.

Finalmente, como Vygotski (1993) señaló, desde los tres años los/as niños/as usan formas conceptuales que pueden hacer creer que poseen un pensamiento desarrollado; esto hace que quienes estudian la formación de la identidad de género cometan la equivocación de ver indicios asociativos como significados consolidados. La relación entre concepto cotidiano de identidad de género y los estereotipos es un tema pendiente que deberá profundizarse más. Para ello será necesario otro método, tal vez el genético-experimental, que posibilite poner al descubierto la dinámica tanto cultural como personal de dicha relación.

\section{Referencias}

ÁLVAREZ-GAYOU, J. L. Cómo hacer investigación cualitativa. Fundamentos y metodología, México: Paidós, 2003.

BEM, S. Gender Schema Theory and Its Implications for Child Development: Raisin Gender-aschematic Children in a Gender-schematic Society. Sign, Chicago Journals, Vol.8 No.4 Sumer, pp. 598-616, 1983. DOI: https://doi.org/10.1086/493998.

CERVANTES, J.C.; CHÁVEZ, S. Desarrollo de la identidad de género desde la Psicología Histórico-cultural. Revista Estudios Culturales Julio a Diciembre, Vol. $1 \mathrm{~N}^{\mathrm{o}} 20$ Universidad de Carabobo, pp. 171-196, 2017.

DAVIES, B. Sapos y culebras y cuentos feministas. Los niños de preescolar y el género. Madrid: Ediciones Cátedra, S.A., 1994.

DELVAL, J. Descubrir el pensamiento de los niños. Introducción a la práctica del método clínico. Barcelona: Paidós, 2001.

DIO BLEICHMAR, E. Género y Sexualidad: nuevas perspectivas en el Psicoanálisis contemporáneo. En: López, T. y Oliva, A. (editoras). Crítica feminista al Psicoanálisis y a la filosofía. Madrid: Editorial Universidad Complutense de Madrid, pp. 49-92., 2003. 
ELKONIN, D. Psicología del juego. Madrid: Visor, 1980.

ELKONIN, D. Hacia el problema de la periodización del desarrollo en la edad infantil. En: Solovieva. Y. y Quintanar, L. (coordinadores). Las funciones psicológicas en el desarrollo del niño. México: Trillas, pp. 191-209, 2009.

FINE, C. Cuestión de sexos. Barcelona: Roca Editorial, 2011.

FRANZ, S. Gender Identity and Gender Stereotypes as Interacting Influences on Children's Adjustment. Florida: Florida Atlantic University, 2009.

GARCÍA-MINA, A. Desarrollo del género en la feminidad y la masculinidad. Editorial UNED Madrid, 2003.

HERRANZ, P. y SIERRA, P. Psicología Evolutiva I. Vol.2 Desarrollo Social. Narcea Ediciones, Madrid, 2005.

INFANTE, V. La masculinidad desde la perspectiva de género, Serie género y trabajo social $\mathrm{N}^{\circ} 1$ en Perspectiva de género, (Coord.) Julia del Carmen Chávez Carapia. UNAM, México, 2004.

JAYME, M.; SAU, V. Psicología diferencial del sexo y el género. Barcelona: IcariaAntrazyt, 2004.

LAMAS, M. Cuerpo, diferencia sexual y género. México: Taurus, 2002.

LURIA, A. Conciencia y lenguaje. Visor, Madrid, 1995.

MACRAE, C., STANGOR, Ch. \& HEWSTONE, M. Stereotypes and Stereotyping. The Guilford Press, New York. 1996.

MARTÍNEZ, I.; BONILLA, A. Sistema sexo/género. Identidades y construcción de la subjetividad. Valencia: Universidad de Valencia, 1999. DOI https://doi.org/10.5944/rppc.vol.5.num.1.2000.3889.

PERROT, M. Mi historia de las mujeres. Buenos Aires: Fondo de Cultura Económica, 2009.

POULIN-DUBOIS, D. et al. "Men don't put on Make Up: Toddlers' Knowledge of the Gender Stereotyping of Household activities". Social Development, Malden, MA, USA, v. 11, n. 2, pp. 166-181, 2002. DOI: https://doi.org/10.1111/1467-9507.00193.

ROCHA, T. Desarrollo de la Identidad de Género desde una perspectiva PsicoSocio-Cultural: un recorrido conceptual. Revista Interamericana de Psicología, Vol. 43, Num. 2, pp. 250-259, 2009. 
SCHAFFER, R. Desarrollo Social. México: Editorial XXI, 2000.

SERBIN, L. et al. Gender-seterotyping in infancy: Visual preferences for and knowledge of gender-stereotyped toys in the second year. International Journal of Behavioral Development, Los Angeles, CA, USA, v. 25, n. 1, pp. 7-15, 2001. DOI: https://doi.org/10.1080/01650250042000078.

SERBIN, L.; POULIN-DUBOIS, D.; EICHSTEDT, J. "Infants' Responses to Gender-Inconsistent Events". Infancy, 3(4), pp 531-542, 2002. DOI:

https://doi.org/10.1207/s15327078in0304_07.

SHARDAKOV, M. Desarrollo del pensamiento en el escolar. México: Grijalbo, 1987.

SIMÓN, E.; CREMADES, M. “Aprendizaje en las relaciones de género e intervención coeducativa" en Miguel Ángel Santos (coord.) Aprender a convivir en la escuela. Universidad Internacional de Andalucía y Akal, Madrid. 2003.

TREMBLAYD, R. et. al. "Physical Aggression During Early Childhood:

Trajectories and Predictors". Pediatrics Vol. 114 No.1 July: p.43-50 Illinois. 2004.

UNESCO. Atención y educación de la Primera infancia. Informe Regional América Latina y El Caribe, Moscú. 2010.

VYGOTSKI, L. S. El desarrollo de los procesos psicológicos superiores. Grijalbo, Madrid. 1979.

VYGOTSKI, L.S. Obras escogidas. Tomo I. Madrid: Visor, 1991.

VYGOTSKI, L.S. Obras escogidas. Tomo II. Madrid: Visor, 1993.

VYGOTSKI, L.S. Pensamiento y Lenguaje. Paidós, Barcelona. 1995

VYGOTSKI L.S. Obras escogidas. Tomo IV. Madrid: Visor, 1996.

VYGOTSKI, L.S. La imaginación y el arte en la infancia. México: Fontamara, 1997.

WERTSCH, J. Vygotsky y la formación social de la mente. Barcelona; Paidós, 1988. 